\title{
Critical Variables of bUSiness failure: A REVIEW AND CLASSIFICATION FRAMEWORK
}

Marius Pretorius

Department of Business Management, University of Pretoria

\begin{abstract}
Failure is a phenomenon that ventures face during all stages of the life cycle and requires insight into its causes before it can be reversed. The scientific literature on failure is, however, spread over multiple disciplines. This study's line of enquiry firstly reviews the documented research (both theoretical and empirical) encompassing the phenomenon 'business failure' on a multidisciplinary basis. A conceptual framework is then proposed for categorising variables into four sub-domains namely: signs and prediction; causes and preconditions; recovery; and cognition and learning. Better understanding of the failure phenomenon is achieved. The methodology applied is fundamentally based on grounded theory interpretation with a focus on classifying the identified relevant variables.

(Key words: Decline, Failure, Trouble, Crisis, Turnaround)
\end{abstract}

JEL E32

\section{1}

Introduction

This article surveys the theoretical and empirical literature on business failure for variables associated with it. The article's perspective is interpretative in nature as the literature is widely spread over many journals of varied interests, and therefore business failure often appears ill defined and "messy" for research purposes. The main purpose of this study is to review the literature and map the territory meaningfully to direct research and entrepreneurial application through the failure domain.

Firstly, after applying an interpretive review to the scientific literature, a classification framework is proposed for business failure (based on "grounded theory" principles). The framework identifies four sub-domains of failure based on the underlying relationships between variables associated with failure. These subdomains are: signs and prediction; causes and preconditions; recovery; and cognition and learning from failure, each sub-domain with its own variables. Secondly, each of the subdomains is explored for its key variables.
Beyond scholarship, this article has implications for entrepreneurs, business owners and business managers alike. The conceptual framework clarifies the interrelatedness of variables underlying the generally ill-defined and complex phenomenon of venture failure. The variables that shape the sub-domains are important to understand, as their existence and combination within the preconditions determine the severity of venture decline and the turnaround situation. Entrepreneurs could make use of this improved understanding to reduce high failure rates of 80 to 90 per cent as reported by Knott and Posen (2005: 617).

\section{2}

\section{Research questions}

What exactly is business failure? Under what conditions does it arise, and by what specific mechanisms? What key variables can be blamed as causes for business failure? Also, what are the key dimensions of failure as a domain? Should corporate and entrepreneurial ventures consider failure in the same way? Furthermore, is it important to know the answers to these questions? 
Failures attract attention all the time, whether in business (start-up and mature), entrepreneurship, strategy, risk, management, finance, accounting, organisational culture, change or environment related journals. It appears that failure is inherent to the science of business management (Altman, 1983: 15). If failure is indeed central to the entrepreneurial thrust of ventures, better understanding of the domain benefits the science overall. Classification assists understanding and generally has four objectives: differentiation; generalisation; identification and information retrieval that could benefit researchers in the failure domain (Chrisman, Hofer \& Boulton, 1988: 414).

Understanding business failure presents an enormous theoretical challenge that fundamentally remains to be met, probably because past efforts were more concerned with prediction than with understanding. That such a challenge has largely gone unanswered is relatively easily understood (Cybinski, 2001: 39; Shepherd, 2005: 126). The lack of a definition of failure is partly responsible for the lack of understanding of the concept (Shepherd, 2005: 124). Existing research also appears problematic because of the current definition of failure and the way failures have been measured in the past (De Castro, Alvarez, Blasick \& Ortiz, 1997: 1).

We know from a growing body of knowledge (Crutzen \& Van Caillie, 2007: 8) on the topic of failure that research articles on failure are scattered across business, management, financial, psychology, entrepreneurial and many other journals. This study could find no proof that these works have ever been comprehensively reviewed. It further seems that there is no specific body of science to which failure exclusively belongs. Existing writings about failure issues diverge into several fields and while many different approaches to failure research exist, the focuses and objectives between researchers create an ill-defined domain with several overlapping fields making up the domain (Shepherd, 2003: 318). This study focuses on failure in business ventures, but does not ignore failure in other organisations such as government ventures. While this study prefers the term "venture", it uses it interchangeably with "business", "firm" and "organisation" according to the way different authors reported their research in the literature.

Business ventures usually hover somewhere between the extremes of the success-failure continuum and the potential consequences of failure have a significant and interesting impact on business strategy decisions (Cybinski, 2001: 31).

\section{3}

\section{Aim of this study}

This study has two principal aims: Firstly it seeks to review with an interpretative perspective and at the same time order the scientific literature on business failure which is fragmented (Crutzen \& Van Caillie, 2007: 9). Secondly it attempts to consolidate and strengthen the theoretical basis of business failure as a phenomenon by systematically categorising the key findings of existing studies to produce an improved understanding of failure. To this end, the study provides firstly a review (within the space limitations) that classifies variables identified in past studies into coherent sub-domains, and secondly reviews the key findings of these studies focusing on main contributing articles.

Metaphorically, this study follows the physical law that results in white light refracting into many colours when projected through a glass prism. In the same way, a sharp light is shone on "failure" as a phenomenon to find new insights when the light is seen from alternative angles.

The overriding objective is therefore to develop an account of the failure phenomenon that identifies major constructs, their relationships to failure and the context and process involved, thus providing better understanding of the phenomenon that goes beyond a descriptive account.

\section{4 \\ Method of review}

The specific research need identified in this study is one of better understanding and sense making of the failure phenomenon. The methodology adopted in this study was selected because primary sources of failure are limited 
(especially in developing countries), as failed firms disappear and entrepreneurs of failed ventures rarely like to talk about the reasons that led to failure. Even when they do speak out, the explanations are likely to have self-reporting and retrospective reporting biases (Shepherd, 2005: 126).

Scientific resources from ABI-Inform, Ebsco-host, Proquest, Blackwell and other databases were searched for titles published since 1985. Age of publication was considered less important than relevance and contribution to the body of knowledge of failure.

At first a search for "failure" combined with the keywords business, venture, firm or organisation was conducted. All searches were keyword-based and narrowed down by using the different keyword variants identified during the process. As the articles (data) were obtained, searches were extended to include associated terms such as crisis, decline, discontinuance, distress and more. All articles were scanned based on titles and abstracts that led to a first complete reading of each article that was deemed to cover failure-related issues, in a way similar to that described by Forbes (1999: 417) when classifying the literature on cognitive biases of entrepreneurs.

Second- and third-round searches were conducted using author names in addition to keywords for cross-referencing. Thereafter specific journals were searched. Key journals included the Journal of Business Venturing, Entrepreneurship Theory and Practice, the Academy of Management Review, Sloan's Management Review, the Academy of Management Executive, the British Journal of Management, Administrative Science Quarterly, Long Range Planning, Strategic Management Review, The British Accounting Review, Organisational Science and the Journal of Small Business Management but were not limited to these. References of important articles were then searched and accessed to build up an extensive list of articles.

After mapping the definitions through a snowball process (not reported in this study), articles covering all failure-related terms were investigated to identify more references. These reference articles were then obtained and the process repeated to identify the key works referenced. The abstracts of the articles were read (analysed) and those papers that in fact represented failure-related issues, as understood by this study, were selected. Thereafter each article was assessed and key concepts were identified and reported. Concepts were categorised into sub-domains (categories) of failure-related issues and reported individually with their specific contributions. This approach was based on Corbin and Strauss's (1990: 7) grounded theory research. As the sub-domains became clearer, each individual article was further explored for its key contributions. The process of adding articles was never officially stopped but drifted towards closure as no more "useful new information" came forth in accordance with the categories suggested by the grounded theory research process.

As the research progressed and probed the different data bases, failure was associated with bankruptcy, liquidation, insolvency, crisis, decline in performance, decision making, collapse, crashing, accounting practices, project failure, distress, trouble, systems failure, being non-successful, and more. Therefore the eventual search terms focused both on business, organisational, corporate, venture, enterprise (what fails) and decline, failure and turnaround (what is failure) and less on prediction of future failure.

Finally, a conceptual framework for classifying the literature was proposed. Each article was scrutinised for confirmation of concepts, additional concepts and variances under different conditions and contexts. Key article contributions were then reported in some detail and thereafter, additional contributions were added to each category as they developed over time and contributed to or enhanced the understanding of constructs. One of the principles of grounded theory research stresses the requirement for concepts to be repeatedly present in the new data (Corbin \& Strauss, 1990: $7)$. Focus was placed on literature references that seemed well cited or even summarised previous works and once a construct was sufficiently described the literature was not further exhausted. 
5

\section{Findings}

The findings of the research are reported by proposing a conceptual classification framework to govern the thinking and interpretation for the rest of the study. The proposed categories are actually the final result of the study process although they are reported early in the findings section as they contain the main sub-domains of the failure phenomenon. Some key references are then cited along with their major contributions to the failure phenomenon body of knowledge, to explore similarities, variations and overlaps between and within the sub-domains.

\subsection{Categorising the critical variables of the failure literature}

When the selected articles were evaluated, the results pointed towards the failure phenomenon as having four sub-domains (categories) each containing variables determined by the focuses of researchers. In order to holistically envisage the integrated nature of the failure phenomenon, Figure 1 was created to guide the reporting of the findings. The proposed framework is the final product of many alterations to the initially conceived framework. True to the suggestion of Corbin and Strauss (1990), every time the framework was challenged by the principles of categorising, it had to be amended. Although the framework was conceptualised after reading the articles repeatedly and classifying them, the framework is reported at this early junction to benefit the reader and enhance ultimate understanding of this complex phenomenon. From the literature cited and the concepts identified, four core research sub-domains were found underlying the research domain. Each domain contains several focus areas that were associated with it.

Figure 1 shows the conceptual model of failure with the overlapping that exists between the subdomains, confirming their close relationships. These four core sub-domains are:

- Signs and prediction of decline

- Causes and preconditions leading to decline and failure

- Recovery (intervention actions)

- Cognition and learning during failure.

The next section explores the sub-domains individually, and thereafter the relationships between them are explored to complete the discussion of findings.

Figure 1

Failure conceptual classification framework (with sub-domains and key variables) of the failure literature [Own compilation]

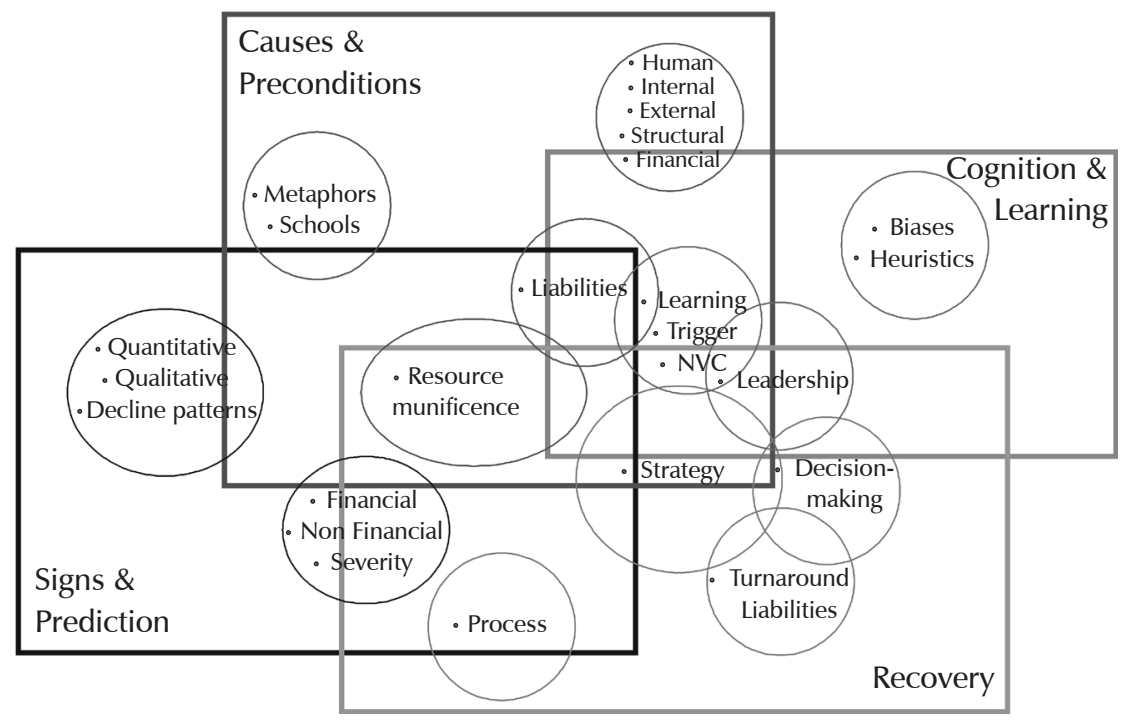




\section{6}

\section{Causes and preconditions of decline sub-domain}

Signs and causes of decline often appear to be used interchangeably, and at the same time are not defined clearly in the literature. It may, however, be critical for this study to briefly distinguish between them, even if it is purely from a dictionary perspective. Causes refer to that which produces an effect, consequence or result (Universal Dictionary, 1988; MerriamWebster Online dictionary, 2008). Causes, therefore, point towards the sources as reasons or variables that are responsible for the presence of decline or failure. Causes therefore create effects or signs. This section explores causes of decline as part of the causes and preconditions sub-domain, while a later section explores signs of decline as part of the signs and prediction sub-domain.

\subsection{Causes of failure}

Fredland and Morris, as far back as 1976, pinpointed the causes of failure as largely a matter of definition and suggested that one cannot isolate the 'causes' of failure - indeed, they said, any attempt to do so is a futile exercise which boils down to ascribing blame and nothing else (Fredland \& Morris, 1976: 8). Still, many researchers pursue this avenue in their research. The factors leading to business failures vary (Charitou, Neophytou \& Charalambous, 2004: 465). They report that economists attribute the phenomenon to high interest rates, recessionsqueezed profits and heavy debt burdens. Reasons vary depending on the researcher's focus. Longenecker, Simonetti \& Sharkey (1999: 503) suggest four schools of thought about the causes of failure, namely: failure at the top; customer and marketing failures; financial management failures; and system and structural failure. These reasons concur with others as reported next.

\section{Human causes associated with failure}

Human causes, in this text, relate to factors such as leadership, management, individual skills and behaviour (or lack thereof) and link closely to the cognition and learning sub-domain discussed later. Lorange and Nelson (1987: 42) introduced five specific categories of human failure causes. These are briefly listed as: decline, entrapment and self-deception; hierarchy orientation; cultural rigidity; desire for acceptance and conformity; and too much consensus and compromise. Clearly their perspective was leadership and management focused and related to larger ventures.

There are also specific human attributions of "dysfunctions" associated with decline that include: scapegoating (blaming leadership); resistance to change; turnover as competent staff start to leave; low morale; fragmented pluralism (special interest groups that become more vocal); loss of leadership credibility; and internal conflict (competition and infighting) (Cameron, Whetten \& Kim, 1987: 128). Interestingly, though, they conclude that there are no statistical differences between declining and stable organisations in their sample for the different factors, but posit that declining and stable organisations differ from growing organisations for these factors (p135).

D'Aveni (1989:577) concludes that managerial and strategic problems cause decline, while decline in turn causes managerial and strategic problems in a "vicious cycle pattern". This he describes as strategic paralysis that disables the firm from finding and pursuing new directions. He suggests that managerial imbalances are causal to this paralysis. Weitzel and Jonsson (1991: 7) approach failure as a downward spiral of decline. They report five stages associated with decline that describe increasing levels of problems that are harder to reverse the further the slide progresses. According to them, the stages are: the blinded stage; the inaction stage; the faulty action and faulty implementation stage; the crisis stage; and the dissolution stage. These findings point towards the importance of leadership and management's ability to recognise change and react properly and in time as these factors are crucial to reversing decline (Cressy, 2006: 104; Longenecker, Neubert \& Fink, 2007: 146; Allio, 2007: 12; Okpara \& Wynn, 2007: 24). 


\section{Internal and external causes associated with failure}

Boyle and Desai (1991: 35) postulated a list of 24 apparent factors (causes) of failure in small firms that they group into four categories based on their environmental (internal or external) origin and whether they are administrative or strategic in nature. It seems that contrary to conventional wisdom, the majority of businesses fail because of internal factors affected by managerial action (or non-action) and discipline. Theng and Boon (1996: 47) confirmed that endogenous factors were viewed as significantly more important than exogenous factors when ranking causes of failure as rated by entrepreneurs of small and medium enterprises in Singapore. Their findings indicate high operating expenses; lack of capital; short-sighted view of the future; lack of control over cash; lack of knowledge of the company's product; and inappropriate marketing strategy as the top six endogenous causes of failure. External environmental change is a growing reality for all firms (large and small) and requires ventures to be more alert to external causes of failure.

\section{Structural causes associated with failure}

There are various structural causes associated with decline including: increased centralisation; lack of long-term planning; curtailed innovation; departure of competent staff; loss of resource slack; fragmented pluralism; and non-prioritised cutbacks (Cameron et al., 1987: 128). Other elements of this category include the age, size and life cycle stage of the venture.

In their investigation and analysis of bankrupt firms, Thornhill and Amit (2003) compared industry change, general management, financial management and market development variables associated with different stages of business development. Using the resource-based view, Thornhill and Amit (2003: 500) suggest that young firms are more likely to suffer from resource and capability deficiencies than older firms, which is the essence of the "liability of newness" (Zacharakis, Meyer \& De Castro, 1999: 2; Shepherd, 2005: 124). Liability of newness has a lot to do with a firm's seeking legitimacy with its suppliers, clients, creditors and other organisations in the industry. This legitimacy increases as the firm learns to cope with the challenges of the industry. Liability of newness is dissimilar, although closely related to "liability of smallness", which refers to size limitation that may exclude a venture from competing in an industry. Kale and Arditi (1998: 459) connect liability of smallness to a firm's inability to create processes such as learning and inventing roles, and to develop trust and cooperation between members in the organisation. Newness therefore implies lack of organisation learning and legitimacy, coupled with smallness, and appears to be the primary factor underlying the high probability of failure. A newly established firm has an initial stock of assets, goodwill, trust and financial resources that provide the firm with a buffer for the initial period to establish exchange relations with clients and creditors and other organisations to channel resources to the firm (Kale \& Arditi, 1998: 459). The initial resources and endowments reduce the risk of failure even if the performance is not quite satisfactory. After this period, when the buffer is depleted, the firm faces the "liability of adolescence". The probability of failure during this period rises sharply.

Older firms, having presumably developed valuable resources and capabilities in their evolution from being young to being older, will be more prone to the hazards of environmental change and therefore suffer from "liability of obsolescence" under the resource-based view. Stanworth, Purdy, Price and Zafaris (1998: 56) confirm the broad pattern that young firms are more likely to fail than old firms and that very small firms are more likely to fail than large firms.

Fredland and Morris (1976: 10) state that large firms are less likely to face capital market discrimination, are more apt to survive exogenous crises or serious managerial mistakes, are more efficient to the extent that scale economies exist, and are also better managed on average than small firms. Thornhill and Amit (2003: 505) conclude that failure while young is more likely to be due to deficiencies in general management and financial management. Failure when older is more likely a function of external market forces. Industry effects were also evident as contributors. 
The study of Kale and Arditi (1998: 463) confirms that an age-dependent pattern of failure exists in which the risk of business failure increases in the first few years of a company's life, reaches a peak point, and decreases thereafter as the company ages.

Bruno, McQuarrie and Torgrimson (1992: 294) report reasons for entrepreneurial failure (failure early in the venture life cycle) from interviews with founders to include: product/ market factors (timing, design, distribution/ selling and business definition); too great a reliance on one customer; financial factors (initial undercapitalisation, assuming debt too early, venture capital relationship); and managerial/key employee factors (ineffective team and personal problems). While there are similarities between entrepreneurial failure and business failure, these reasons differ to some extent from the causes reported by Boyle and Desai (1991) as well as Weitzel and Jonsson (1989), in that the focus is different. It is apparent that depending on the life-cycle stage a venture is in, the specific causes for failure vary accordingly and therefore the entrepreneurial phase shows different reasons for failure than, for example, the maturity phase.

Henderson (1999: 281) confirms the existence of both liabilities of newness (where selection processes favour older and more reliable firms with social legitimacy) and obsolescence (where a firm becomes highly inertial and its "founding imprint" becomes increasingly misaligned with its changing environment). He adds the liability of adolescence (firms that are past the use of their founding assets but that have not yet accumulated sufficient skills and know-how). Henderson suggests that contrary to general thinking, failure rates increase in adolescent firms as the impact of their original resources endowments have expired. However, the associated failure rates differ, depending on the long-term strategies chosen by firms.

The reference to entrepreneurial failure and liability of newness points to some relationship with the life-cycle stage to moderate the signs and causes of failure. Terms such as start-up failure and liability of obsolescence confirm the life-cycle metaphor borrowed from the ecological sciences. These liabilities, one can argue, each describe a set of configurations that exist for the causal factors of decline and failure. In the same way the cause configurations vary with age (young $v s$ old), size (small $v s$ big) and life cycle stage (infant, growth, mature or decline). Each set of configurations is associated with a different level of risk towards a venture.

\section{Financial causes associated with failure}

Finance is often cited as the ultimate cause of failure. Most works, however, use finance as a predictor of potential failure (bankruptcy) and it is suggested that weak cash flow is due to business-related causes rather than being the cause of failure itself (Ooghe \& de Prijcker, 2008: 223). Topping the list is venture debt (leverage) (Bollen, Mertens, Meuwissen, Van Roak \& Schelleman, 2005: 8; Scherrer, 2003: 57), whether being too much or incorrectly structured. Financial conditions follow, being due to working capital deficiencies or cashflow influencers such as stock levels, credit days and others (Hofer, 1980: 21). Financial causes are well described in the literature as they form the basis of quantitative prediction models as described later. This study is biased against financial issues in its exploration because prediction forms such a large sub-domain within the existing failure literature. It is however further explored under the signs and prediction sub-domain.

\subsection{Preconditions of failure}

Corporate decline generally does not stem from a single factor; it results from an accumulation of decisions, actions and commitments that become entangled in self-perpetuating workplace dynamics (Moss Kanter, 2003: 61). A precondition refers to a condition (or set of configurations) that must exist or be established before something can occur, thus it is a prerequisite. Francis and Desai (2005: 1221) refer to preconditions as contextual factors. Lorange and Nelson (1987) describe the configurations that lead to decline in business performance, especially after the firms have been successful for a period of time. They confirm that preconditions do exist and that the signs are often invisible, especially during the early stages of the decline process. Richardson, 
Nwankwo and Richardson (1994: 9) describe a range of environmental configurations that lead to different types of business failure crises.

These preconditions to failure are often presented as metaphors. Each metaphor suggests a configuration that would require a different intervention to turn the business around towards improved financial performance. Richardson et al. (1994: 9) use four 'frog analogies' as metaphors to describe the specific preconditions that would lead to each type of failure and differentiate how these would appear different for small and large ventures. They further equate organisations in their metaphors with leader type, personality and style to explain the configurations. There are four analogies. Boiled frog metaphorically describes organisational leadership that suffers from introversion and inertia in the face of environmental change (confirmed by Chowdhury and Lang, 1993: 9). Drowned frog describes organisational leaders that try to do everything through hyperactivity and ambition to perform well. After early success, the leadership pursues high growth through uncontrolled diversification and an eventual loss of focused strategic competitive advantage occurs. The Bullfrog metaphor represents a leadership that spends money from the organisation (which it cannot afford) on personal benefits that often can be categorised as aimed at prestige and establishing an image in the community. The bullfrog's behaviour raises ethical questions and proper governance guidelines are clearly not complied with. Tadpole refers to a start-up venture that never turns into a proper business, or the big new project in a large organisation that drags it under.

Arrogance and success seem to lie at the heart of much of business failure in the research of Richardson et al. (1994). However, whereas the 'boiled frog' managers, for example, may exhibit arrogance based on their longstanding position as a major market player, the 'drowned frog' managers exhibit arrogance based on the belief that their early and often remarkable success can be reproduced time after time, notwithstanding the new and increasingly different and bigger contexts in which success is sought. The 'bullfrog' shows arrogance of a different kind, feeling untouchable and indestructible, while not acknowledging the wrongdoing that hurts the business financially.

Bollen et al. (2005: 15) expanded the same metaphors into a classification system for evaluation of failures in European firms. They refer to the tadpole as the unhealthy firm, the drowned frog as the firm that is over-ambitious and shows extreme growth, the boiled frog as a firm that is unable to adapt to environmental change, while the bullfrog refers to management involvement in unethical and fraudulent behaviours. Their conclusion confirms that no single factor is dominant and can be used to explain the majority of business failures of large public companies in Europe. While these frog metaphors are helpful, they focus strongly on the leadership variables of decision-makers (supporting the human factor perspective), which are not necessarily conclusive as determinants of the preconditions, as other authors (like Stead \& Smallman, 1999) describe alternative configurations of variables that may determine specific preconditions to failure.

The preconditions for and triggers of failure are specifically relevant to understanding decline, while crisis and recovery periods are relevant to the reversal of decline (turnaround). Exploring these individually contributes interesting insights to causes and preconditions of business crises and supports the interrelation with the other three sub-domains:

- Preconditions include several variables such as the apparent "normality" within an organisation that is associated with the culture within that firm (beliefs, norms, practices and tacit heuristics). Preconditions may firstly evolve through the accumulation of unnoticed sets of events that are at odds with a venture's accepted beliefs about hazards and the norms for their avoidance. In this regard, management beliefs and rigidity are key contributors to this accumulation of failure preconditions with the venture's leaders clearly unaware that they encourage this development. Secondly, decoy phenomena occur when a problem is perceived, but the action to deal with the problem then detracts attention from the problems that eventually cause the disaster. 
- No two triggering events are exactly alike but there are some similarities within an industry, such as a large exposure or large bad loans. The trigger event is equated to the last straw breaking the camel's back.

The main contributions of Stead and Smallman's (1999) work are twofold. Firstly, their application of the crisis process and its fit to the banking industry cases described appear to have a wider application to more industries thus implying a generic value. Secondly, their principle of preconditions confirms what other authors have found and highlights the importance of failure preconditions. Pandit (1995: 13) confirms the concept of preconditions in his theoretical framework of corporate turnaround. He includes preconditions in the framework as the category of "contextual factors" that govern turnaround strategies. These factors include variables such as: the causes of decline; the severity of a crisis; the attitude of the stakeholders; industry characteristics; changes in the macro environment; and the firm's historical strategy.

In summary, the following constitute the logic about preconditions based on the literature:

- Preconditions exist because decline and failure cannot be ascribed to a single cause and depend on a set of complex causal configurations making up each unique situation.

- The severity of the preconditions compounds as decline progresses over time towards failure (therefore the definitions as proposed).

- Preconditions determine and are determined by the magnitude (severity) of the decline and hence govern the success of the potential recovery (turnaround).

The next sub-domain of the failure conceptual framework is signs and prediction of failure.

\section{7}

\section{Signs and predictions of failure sub-domain}

Within the body of literature on venture failure, the largest section deals with this sub-domain - the signs and predictions of failure.

\subsection{Signs of decline}

Signs refer to things that point to the presence or existence of a fact or condition (cause) that is not immediately evident (Universal Dictionary, 1988). In this study, the word sign is taken to mean something which points to (acts as an indicator of) possible causes of failure (or decline) and these pointers are referred to as "warning signs". Walshe, Harvey, Hyde and Pandit (2004: 202) suggest the use of symptom terminology to better explain the concept of signs that can be both chronic (gradual) or acute (triggers) and that may precipitate a crisis. Signs cannot, however, cause failure but are purely indicators that failure causes are present within a certain situation. D'Aveni (1989) describes organisational decline as a pattern of decrease over time in a firm's internal resources as measured by an index of internal resource munificence.

Based on the causes of decline reported earlier, Lorange and Nelson (1987: 43) describe several early warning signals that can serve as indicators of failure causes to the observer. Weak signals are obviously much harder for managers to see, understand and take seriously than strong ones. By definition, weak signs appear to be subjective and vague and would probably require intimate knowledge about the specific venture and its environment before meaningful measurement could be done. However, evaluation of such signs is based on perceptions of the respondents that may be subject to several types of cognitive bias. Still, the main conclusions that can be drawn from Lorange and Nelson's (1987: 43) contribution are that:

- Organisational performance almost always slacks off following a period of economic success.

- Organisational complacency sets in if not zealously avoided.

- Preconditions develop as a result of complacency brought about by the good times.

- Signals are less clear during the early phases of the decline.

- There are complex interactions between the contributing causes and these would vary from venture to venture. 
Signs are more visible when decline is severe and approach invisibility when decline is slight. The main value of signs is to predict oncoming failure.

\subsection{Prediction of decline}

The second element of this sub-domain is prediction. It would be easy to become overwhelmed by this category of research works, but for the purposes of this study, distress and failure prediction is explored mainly because of its close association with the causes and preconditions of decline sub-domain explored earlier.

A substantial amount of research has been conducted into the prediction of corporate failure (Smith \& Graves, 2005: 304). Prediction of failure is found to be the central topic in the financial accounting literature (Bollen et al., 2005: 15). It can therefore be seen that distress prediction is of specific interest to financial institutions and government agencies as they wish to be protected against risk of failure when funding ventures (Altman \& Narayanan, 1997: 53). Balcaen \& Ooghe (2005: 24) confirm that corporate failure prediction has become a major research domain within corporate finance after summarising 35 years' research on failure prediction. Despite the bias towards financial and quantitative data, this study provides a basic exploration of prediction under two headings, namely financial and non-financial prediction.

\section{Financial prediction of failure}

The value of understanding failure is surely in the ability to contribute either towards prevention thereof, through looking for early signs of decline and causes or to respond to potential failure through recovery interventions. Consequently the ability to predict failure has significant value especially for financiers and venture capitalists. Several models have therefore been developed and tested over the years to predict failure. Mostly, these models use bankruptcy as the independent variable. Pompe and Bilderbeek (2005: 847) found that virtually all ratios they investigated had some predictive power. Prediction models have evolved over time and prior research claims their accuracy
(Keasey \& Watson, 1991: 81). The models used include mainly multiple discriminant analysis (MDA), linear discriminant analysis (LDA) and quadratic discriminant analysis (QDA) and are used to attempt to predict failure before it happens. For a variety of reasons, MDA appears to be the de facto standard for comparison of distress prediction models (Altman \& Narayanan, 1997: 2).

It appears meaningless, however, to predict failure if the prediction cannot be used to prevent the actual failure, and therefore the ability to quantify early signals is most important. Altman and Narayanan (1997: 1) surveyed the works by academics from 21 countries and concluded that they shared a striking similarity in their approach to distress prediction, and nearly every study contrasts the profile of failed firms with that of healthier firms to draw conclusions about the coincident factors of failure.

Most prediction models depend on accurate quantitative data (financial ratios) over several years prior to failure (Steyn-Bruwer \& Hamman, 2006: 7). This is problematic especially for micro and small ventures that are known to be weak in administration and record keeping. Prediction models therefore appear more relevant for larger, older firms and firms from countries with strict reporting policies. Bollen et al. (2005: 16) report the 1968 model of Atman and the 1980 model of Ohlson as important contributors and yardsticks to prediction of failure, despite the ages of the models, while Laitinen and Kankaanpää (1999: 67) report no significant difference in prediction value of six alternative prediction methods (linear discriminant analysis, logit analysis, recursive partitioning survival analysis, neural networks and human information processing) applied to Finnish data sets. Of course, these models are dependent on the combinations of ratios used to drive their predictive value.

Financial prediction is clearly important as indicated by the fact that the largest portion of the literature found during the searches done for this study concerned prediction. Financial prediction is not without limitations, however, some of these can be overcome through the use of non-financial prediction models. 


\section{Non-financial prediction of failure}

Compared with the representation of financial prediction literature, the non-financial research reported appears almost insignificant. The multi-dimensional nature of failure, however, suggests that several variables of a non-financial nature play a role as both signs and causes of failure. Keasey and Watson (1987:351) reported that the use of non-financial prediction variables improves the results achieved with financial prediction, especially for small ventures where accounting data is often suspect.

Lussier (1995: 8) reported that qualitative data could provide at least as good predictions as traditional financial ratios. He proposed a model of 15 variables that range from capital, record-keeping, industry experience, management experience, planning, professional advisors, education, staffing, product/service timing, economic timing, age, to partners and parents, minorities, marketing skills and concluded that four out of these 15 variables differed as starting resources between successful and failed firms. Successful firms made greater use of professional advice and developed more specific business plans, while failed firms had less education and more difficulty attracting quality staff. Lussier and Pfeifer (2001: 228) confirmed the same factors as found for United States data to be predictors for Central Eastern European business, suggesting that all these factors have to do with human resource related issues.

Back (2005: 843) evaluated management character, payment disturbances, personal prior payment behaviour, and group membership and payment delays combined with size, efficiency and leverage to predict bankruptcy. The results indicate that the estimated model based on the non-financial variables classified firms even better than the financial ratio model. The implication of the results is that non-financial variables embrace important information in attempts to explain financial difficulties, and when used in combination with financial models generally improve the accuracy of prediction.

Studies seeking to detect signals of a firm's deteriorating condition over time may be more successful in explaining enterprise failure, as one would expect these signals to be produced sequentially for many years beforehand (Cybinski, 2001: 40). However, the time lag of some variables may therefore become problematic and moreover the interventions of management during the distress period can often influence the variables to such extent that trends are not visible.

The use of prediction models confirms the existence of preconditions during decline and for failure, as their uses are based on the different configurations that determine the signs to predict with. Therefore most researchers use comparative studies to measure the signs. Prediction models use mainly ratios or combinations of ratios through MDAs and therefore the models depend on accurate and measurable information. The amount of research work carried out on prediction models strengthens the value of and necessity for early warning signs.

A recent seminal work on failure by Probst and Raisch (2005: 90) describes the logic of failure as dualistic in nature and in the effects contributing to organisational failure. They postulate the factors as excessive versus stagnating growth; uncontrolled versus tentative change; autocratic versus weak leadership; and excessive versus a lack of success culture. Depending on the level of each factor, they describe the failure as resulting from either failure due to burnout syndrome or failure due to premature ageing syndrome. These two types of failure each require a different set of preconditions. This work concludes that failure is a result of deviations from the midpoint (where factors are balanced), depending on the combination of the four factors of growth (quantitative), and change, leadership and culture (all qualitative). It is clear that failure relates largely to qualitative issues that are inherently more difficult to define and measure objectively during research.

Probst and Raisch's study highlights some important wisdom associated with failure, namely the dichotomy leading to the unbalanced outcomes of factors that lead to failure; and that qualitative causes make up three-quarters of the reasons for failing, confirming the complex interrelation between the factors that create the preconditions. 
Bollen et al. (2005: 15) conclude that despite various studies, there is little agreement on what factors are important for failure prediction. This disunion in conclusions can be partly attributed to the fact that studies refer to different periods, countries, industries and specific ventures. Each model must therefore be evaluated on its own merits.

The amount of prediction-related literature forming this sub-domain confirms the search for methods to quantify sets of preconditions in such a way that trends can be used as signs of approaching failure. Financial prediction models aim to improve quantification of signs that can serve as early warning of pending decline or failure (signs) while non-financial prediction models aim to improve financial prediction models by adding non-quantitative variables.

\section{8}

\section{Recovery sub-domain}

"Every company has performance gaps but struggling (declining) companies have wide performance gaps that can endanger their survival. The situation analysis is absolutely essential to ascertain the magnitude of the gap and to determine the availability of specific resources to close the gap. If the gap cannot be closed to achieve at least a break-even return within a reasonable time, the company is not viable" (Unknown)

Following the signs and prediction sub-domain, recovery appears, on the basis of the ease of finding articles during the different literature searches, to be the second-largest sub-domain covered in the literature. It further seems that recovery is really at the centre of failure research - it makes little sense to study the other subdomains if this study is not concerned with the long-term success of ventures through recovery from decline and fighting failure. The recovery of a business that is in real trouble/distress is usually referred to as a "turnaround". However, in this study we use the term 'recovery' and incorporate both venture turnaround and the revival/renewal of businesses facing less threatening problems and less severe declines.

\subsection{Processes for recovery}

Turnaround has mostly to do with strategies after a threatening decline. There appears to be a classic five-step turnaround process accepted and supported by the global Association of Turnaround Professionals (Burbank, 2005: 53), but many others also refer to the process with slight variations in the key steps (Hofer, 1980: 19; Hambrick \& Schecter, 1983: 235; Smith \& Graves, 2005: 307). These steps include: situation analysis; changing the management; emergency actions; restructuring actions; and finally returning to normality (profitability). Some studies suggest a different sequence regarding the first two steps - situation analysis and changing the management.

The turnaround process generally has two key activity stages, namely decline stemming and recovery strategies (Smith \& Graves, 2005: 305). Robbins and Pearce (1992) describe a "turnaround situation" that requires specific strategies (retrenchment and recovery), depending on the cause and severity of the turnaround situation. They propose specific strategies based on combinations of both the retrenchment (confirmed by Bruton, Ahlstrom \& Wan, 2003: 528) and recovery phases of the process. Robbins and Pearce's (1992) process requires action to achieve stability first and thereafter recovery.

Retrenchment as the first step in a two-phase process remains the foundation of business turnaround (Pearce \& Robbins, 1994: 407). They suggest that regardless of the cause or severity of the turnaround situation or longterm competitive strategy used to combat the situation, the most expeditious road to turnaround begins with a sustained retrenchment response (Robbins \& Pearce, 1992: 304). Pearce and Michael (2006: 204) suggest that strategies for turnaround vary when the cause of failure is recession, but remain rooted in the original retrenchment and recovery focuses to make firms recession-proof and to fight the effects of recession.

Given the complexity of failure, Sheppard and Chowdhury (2005: 240) suggest that there are four issues to consider in order to better understand organisational failure, namely: 
- Failure is not typically the imperfection of either the environment (external preconditions) or the organisation (internal preconditions), but rather it must be attributed to both of these forces, or to be more exact, failure is the misalignment of the organisation with the environment's realities.

- Because failure involves the alignment - or misalignment - of the organisation with its environment, it is, by definition, about strategy (confirmed by Carroll \& Mui, 2008: 83).

- Because failure deals with strategy, we can make choices to accelerate it or avoid falling into its clutches (confirmed by Pretorius, 2008: In press).

- Because organisational failure can be avoided even after a decline - rapid or prolonged - the ultimate failure of the organisation really stems from a failure to successfully execute a turnaround.

It is therefore critical to our understanding of organisational decline and failure to recognise that three intertwined factors - a firm's management (including leadership), its environment and the way the firm interacts with its environment (strategy) - all contribute to the specific configuration of variables facing the firm at a point in time. Essentially, recovery from a set of preconditions is therefore about strategy (Kow, 2004: 229).

\subsection{Strategies for recovery}

Many strategies for recovery are reported in the literature, and often similar strategies appear under different terminologies. Hofer (1980) distinguishes between operational (revenuegenerating, cost-cutting, asset-reduction and combination) and strategic (position-changing) turnarounds as the two broad strategies available to the firm in decline. While the distinction is blurred in practice, these strategies are the core ones to be used in the turnaround process and have to do with shorter-term performance and longer-term directional issues that influence the survival of the firm. Hofer's (1980: 27) simple link of the strategies with the break-even graph directs the application of the strategies to different preconditions that could be associated with the different configurations. He suggests that:

- If a business is far below break-even, an asset-reduction strategy is warranted. Such a business must recognise that it should be smaller than it once hoped to be.

- If the business is moderately below breakeven, a revenue-generating strategy is called for. In such a situation, the business does not have enough idle capacity to allow major asset disposal, nor is it close enough to break-even to prosper from cost cutting. The business must make a concerted effort to increase volume.

- If the business is very close to break-even, a cost-cutting strategy is appropriate. Such a strategy will often be sufficient to push the business to acceptable profit levels without exposing it to undue risks.

Sudarsanam and Lai (2001: 183) report empirical results of eight generic turnaround strategies on measures between recovery (distressed firms that attain positive Z-scores by the end of the second year from distress) and nonrecovery firms. The strategies they investigated were: operational restructuring, asset sales, acquisitions, capital expenditure, managerial restructuring, dividend cut/omission, equity issue and debt restructuring. These strategies were evaluated after control for severity of the decline, internal problems, industry conditions and economic conditions. Their findings show that recovery and non-recovery firms adopt similar sets of strategies, and managers of nonrecovery firms restructure more intensely than recovery firms. Nevertheless, non-recovery (failed firms) firms seem far less effective in strategy implementation than their recovery counterparts. Whereas recovery firms adopt growth-oriented and external market focused strategies, non-recovery firms engage in firefighting strategies.

Pearce and Robbins (1993: 618) add strong financial control, product/market reorientation and improved marketing to the list of strategies associated with successful turnarounds. Inkpen (1995: 316) suggests that absence of strategy 
could be interpreted as failure on the part of management. Absence of strategy is most probably shown through absence of decisionmaking, or the inaction stage described by Weitzel and Jonsson (1991). Pretorius (2008: In press) proposes a matrix of strategies in response to different turnaround situations depending on resource munificence and origin of the decline. Hopkins (2008: 5) agrees that correctly determining the turnaround situation has much to do with the eventual success of the chosen strategy.

\subsection{Decision making and action}

Through cluster (factor) analysis, Hambrick and Schecter (1983: 231) identified three "gestalts" (strategy combinations) associated with successful turnarounds (Asset/cost surgery; selective product/market pruning; and increased capacity utilisation and employee productivity) and four gestalts associated with failed turnarounds (significant entrepreneurial initiatives; dramatically reduced monetary expenditures; significant increase in new products; and no distinguishing actions). A gestalt refers to a set of associated actions that together have impact on the success of turnarounds. It is interesting that in most of the cases where turnarounds failed by application of the strategies, firms had relatively high market share, suggesting that top management teams underestimated the severity of their preconditions. Hofer (1980: 28) also proposes market share as an important factor (within the preconditions) affecting choice of a turnaround strategy. High market share is generally associated with strong distribution channels, brand recognitions, already low costs, economics of marketing, and lower human and organisational costs compared with low-marketshare competitors.

It further seems that recovery strategies are largely dependent on factors that the influence decision making of top management teams. Barker and Moné (1998: 1251) suggest that the extent of strategic reorientation by top management teams depends on the extent of mechanistic structure fit created by the top management based on its perception of the unused debt capacity and financial liquidity of the firm (resource munificence). The link between leadership and the process they choose to pursue the strategy is also crucial to the success of the rescue (Harker \& Sharma, 2000: 36)

Decision making is further influenced by the liabilities that turnaround managers face. Pretorius \& Holtzhauzen (2008: 87) describe six liabilities of turnaround that managers must overcome, namely the liabilities of: legitimacy, leadership, resource scarcity, cause origin (strategic vs operational), data integrity and integration. Of these factors, the last, data integrity and integration, has the greatest ability to impact decision making significantly. It is against this backdrop that it becomes imperative to turn attention to the sub-domain of cognition and learning, which significantly impacts on perceptions, and ultimately decisions and actions.

\section{9}

\section{Cognition and learning sub-domain}

"But what is the most important trouble of all? Denial (not the river in Egypt). Denial makes owners or managers unwilling to admit that problems exist. Or worse ... it can blind them to the very problems that are heading their companies towards sure demise" (Collard, 2002: 25).

"Even worse is collective denial (think emperor's clothes and followers unwittingly colluding) where no one volunteers opinion and knowledge is the ultimate pathology of troubled companies" (Moss Kanter, 2003: $62)$.

Several references point towards the thinking of leaders and managers as a driving force to create preconditions. The sub-domain of cognition and learning attempts to better understand the associated thinking of the people (mainly leaders and managers) involved in the processes of failure and turnaround. The cognition and learning sub-domain with its associated elements appears to be the youngest field investigated as well as the one that has generated the most interest since the turn of the century. 


\subsection{Cognition associated with failure}

A growing portion of articles report on the thinking of leadership and top management associated with failure and personal reactions to failure. Cognitions such as rationality and bounded rationality (Eisenhardt \& Zbaracki, 1992: 17), threat-rigidity theory (Barker \& Moné, 1998: 1228), attribution theory (Barker \& Barr, 2002: 963), anti-failure bias (McGrath, 1999: 13), perception (Collard, 2002: 25), selection of strategies (Caroll \& Mui, 2008: 83), start-up biases (Le Roux, Pretorius \& Millard, 2006: 51) and sunk costs presence (Ansic \& Pugh, 1999: 428) are associated with failure insofar as failure is about the thinking of the individual, the management team and the society within the different cultural context and specific firm context.

Threat-rigidity theory proposes that management who are under threat of decline would react by the increased control and centralised decision making that create more mechanistic firms (Barker \& Moné, 1998: 1228). They suggest that more mechanistic firms will respond with less strategic reorientation actions. McGrath (1999: 17) for example, suggests that social norms can render "losing" as shameful. Therefore an anti-failure bias exists because of the tendency to view failure as negative. This anti-failure bias can hinder understanding of the systemic relationship between failure and success. She suggests that real-options reasoning allows more of the possible benefits to failure to be captured. The antecedents to the antifailure bias are: over-sampling success and undersampling failure, leading to incorrect inferences; routinisation, in which practices perceived to be associated with adequate performance are retained and repeated; improvement and imitation, which, like routinisation, decrease the variety of routines available, leading to existing levels of competence becoming the standard; confirmation bias, that tends to make information associated with potential failure less vivid, plausible, viable, or available and factors associated with success the opposite; misattribution of success to one's own actions and failure to exogenous "unlucky" circumstances; negative perceptions of events associated with failure; negative retrospective recollection of events associated with failure; manipulation of metrics to produce measures that reflect success regardless of the actual results; and diversion of resources to support underperforming initiatives for non-economic reasons and thereby delaying preventative action that may be unpleasant.

This cognitive perspective proposed by McGrath (1999: 19) suggests that these antecedents lead to anti-failure bias through several mechanisms based on psychological theory. Overall, this anti-failure bias has counterintuitive negative effects that can interfere significantly with people's ability to make sense of the failure experience and can even cause "anticipatory grief" that business owners experience before acknowledging failure (Shepherd, Wiklund \& Haynie, 2007: 318). This, in turn, means that failures are not "intelligent" and this impairs learning from failure. Cardon and McGrath (1999) report the reaction of entrepreneurs to failure and re-motivation after experiencing failure. They report that the cause of failure is attributed to either innate ability or effort (strategy); the reaction to failure is either a feeling of helplessness and a desire to give up or, by working harder, to improve effort; and a person's tendency to make one or other attribution has been shown to vary with goals, or with how he/she defines success.

The findings of Cardon and McGrath (1999: 9) suggest that when failure is attributed to the level of effort put forth, the entrepreneur is motivated to exert additional effort to ensure the success of the task. Often individuals are even excited by challenges, and seek these opportunities to learn. Alternatively, when failure and problems are attributed to the failure of the ability of the individual experiencing the problems, a helpless response occurs. The individual may believe that he/she does not possess the ability to overcome the problems, and therefore gives up the task. Through an exploratory evaluation of the attribution, reactions and goals of individuals with a high propensity for entrepreneurship, discovered that an attributional approach to failure and re-motivation could approximately be applied to the entrepreneurial context.

The powerful effect of positive thinking and its potential to influence decision making that 
might lead to failure is described by Lovallo and Kahneman (2003: 57). They report that:

- Most people are highly optimistic most of the time. Research into human cognition has traced this over-optimism to many sources.

- One of the most powerful is the tendency of individuals to exaggerate their own talents - to believe that they are above average in their endowment of positive traits and abilities. This tendency is amplified by another - the misperceiving of the causes of certain events. The typical pattern of such attribution errors is for people to take credit for positive outcomes and to attribute negative outcomes to external factors, no matter what their true cause.

- Executives and entrepreneurs are susceptible to a tendency to exaggerate the degree of control they have over events, leading to over-optimism.

- People in general are subject to attribution bias, which is pernicious to effectively forecasting outcomes of strategies, costs and situations.

- Lovallo and Kahneman (2003: 60) point out the bias of underestimating competitive response, which may have serious effects, especially when entering a new market.

- The organisational pressure to accentuate the positive variables of projects leads to ill effects for the venture that may contribute to decline and failure (confirmed by Kriegesmann, Kley \& Schwering, 2007: 270).

- This thinking bias ensures that the forecasts used for planning are over-optimistic and distorts the real picture. Additionally it raises the odds that the projects and strategies chosen will be those with the most over-optimistic forecasts - and hence the highest probability of disappointment.

- These cognitive biases associated with overoptimism lead to overestimation of benefits and underestimation of costs - both typical contributors to a decline in performance.

These biases influence preconditions through the decisions that leaders make and may be linked to causes of failure, whether directly or indirectly. Barker (2005) reports cognitions and biases that lead to incorrect evaluation of sources of decline in ventures and have much to do with how managers faced with decline conditions process complex information. Typically, such managers utilise thinking shortcuts and biases to assist them to deal with information overload and make sense of the complexity associated with these "messy situations" (Conger \& Nadler, 2004: 53). By referring to "traps", Barker (2005: 44) suggests that signs and causes are both elusive as regards generalisation and situationspecific instances. Two categories of these cognitions are reported: traps in perceiving the sources of decline and traps in understanding the sources of decline (Barker, 2005: 44). These can be briefly summarised as:

Pitfalls in perceiving the sources of decline:

- Relying on filtered data such as reports and statements that basically confirm patterns that already exist and mostly have to do with operational data of costs, revenues and manufacturing issues.

- Paying too much attention to information referring to the most obvious, potential flavour-of-the-day or "bandwagon" issues. Attention is then concentrated on these issues and no attention is paid to potential other contributors.

- $\quad$ Selective perception refers to searching for sources within the experience and known environment of the organisation. While this helps with the overload it invites overlooking peripheral issues that may be the real causes of problems (confirmed by Carroll \& Mui, 2008: 84). Associated with this is the reliance on opinions of "trusted" individuals only.

Pitfalls in understanding the sources of decline:

- Self-serving causal interpretations based on a cognitive bias in which credit is taken for success and others are blamed for failure, hence contributing to incorrect identification of the real problem (confirmed by Mellahi, 2005: 269). 
- Experiential and personality influences that lead to a fallback to what was previously known, such as knowledge, experience and culture.

- Problem framing, referring to that fact that the initial perception of the situation's severity may influence how aggressively certain strategies will be selected over others. Thus, if the environment is perceived as very hostile, retrenchment strategies will be applied more aggressively.

Barker (2005: 49) therefore reiterates the role of cognition in decline, indicating the vulnerability of management and therefore the "logic" associated with different decision paths of different managers facing the same preconditions. Much of what failure is about therefore depends on human elements such as decision-making, behaviour and more (Gimeno, Folta \& Woo, 1997: 750).

\subsection{Learning from failure}

The value of better understanding of failure probably lies in learning from it and eventually preventing future failure or pursuing improved recovery strategies. Learning from the failure experience is therefore critical for it to serve as a positive feedback mechanism (Shepherd, 2003: 318) or as an anticipatory mechanism (Shepherd et al., 2007: 318)

Fortunately, more and more research explores the learning associated with failure as a benefit to the firm for use in future decision making. Individuals do not freely and openly share knowledge about the mistakes they have made (Baumard \& Starbuck, 2005: 283). Some members of organisations do not discuss failure and hence do not learn from failures. One reason for this lack of "de-briefing" is fear that colleagues might blame those who participated in failed ventures, and another is managerial hierarchy that reacts to failure by seeking and punishing culprits.

Cannon and Edmondson (2005: 299) suggest that to learn from failure intelligently requires identifying failure, analysing failure and experimenting with failure. They identify technical and social barriers as the main blockages to the process of identification, analysis and experimentation. Shepherd (2003) approaches the failure (closing) of a venture from the perspective of the self-employed person and how he/she learns from the grief recovery process, thereby adding the "affective" angle. The emotions related with the loss and grief and their associated impact on learning and decision making is explored. Based on the emotion literature, Shepherd (2003: 324) proposes that the negative emotional response (grief) to the loss of a business interferes with the ability to learn from the experience. A dual process of grief recovery can minimise this emotional interference, and recovery from grief removes it completely. The "affective" element therefore is an important contributor to the decision making of leaders and managers. Critical reflection (Cope, 2003: 429), which takes place often long after the failure occurred, is part and parcel of this learning process.

Failure is therefore due to not learning rather than learning. Two findings are relevant:

- A venture's leaders' thinking inertia is a frequently reported trigger event for decline.

- A venture's leaders' ability to overcome their thinking inertia is the trigger event for successful recovery (turnaround).

In summary, in the literature of failure one may distinguish four broad categories as subdomains, each consisting of variables that influence its appearance. These are:

- The signs and prediction sub-domain, containing variables such as quantitative vs qualitative signs used for prediction, patterns of decline underlying the decline trend and severity of the predicted cause; and whether financial or non-financial signs are used for prediction.

- These signs depend on the causes and preconditions sub-domain, including causes of human, internal, external, structural and financial origin. Preconditions are often described by metaphors suggesting the complex combination of causes of failure.

- The recovery sub-domain contains variables such as the turnaround strategy, the process supporting the turnaround attempt and decision making during the process. 
- The cognition and learning sub-domain points to research focused on the leadership (including management) as individuals or teams, considering their thinking, typical biases, heuristics that they use and thinking traps they may be subject to during decline when making decisions aimed at recovering from decline.

This concludes the framework where the subdomains, as found through the research process, were reported as the findings of the study. A discussion of these findings now follows.

\section{0}

\section{Observations, discussion and conclusion}

The conceptual framework proposed in Figure 1 confirms both the complexity of the failure domain and the impossibility of generalising about its variables. This is mainly due to the often unpredictable nature of interrelations of these variables as determined by the unique contexts associated with each decline case. While some correlations can be logically deduced, others are not necessarily straightforward. Considerable homogeneity does exist within categories due to association between variables, but some heterogeneity also exists and causes "blurring" of the outlines of the sub-domains.

While financial prediction is the largest body of research reported, at heart, all research appears to be interested in successful recovery (turnaround) as the main research outcome in the venture failure domain.

Within the failure domain there are specific principles that would alter the outcomes of the signs, predictions, causes, preconditions, processes, strategies, cognitions and learning in the sub-domains. These principles and interrelations will be explored in a follow-up paper, mainly because of space limitations.

\section{1}

\section{Key observations from this study}

Assessing the literature led to some observations which in hindsight may appear to researchers to state the obvious, but could be of significant value to entrepreneurs and practitioners. These observations include:

The character of articles on failure that served as data for this study often leans towards some use of metaphors and paradigms that could probably be ascribed to the nonquantitative nature, complexity and number of variables involved in the decline or failure process. Authors tend to find metaphors to describe certain situational contingencies, people, styles and approach combinations. These combinations of configurations play a determinate role in the causes of the decline or failure, while the causes play the same role in the configurations. Typically the principle of preconditions supports this notion, as seen by the failure syndromes (Probst \& Raisch, 2005), frog metaphors (Richardson et al., 1994) and the use of metaphorical decline stages (Weitzel \& Jonsson, 1991).

A second observation is the extent of the signs and prediction sub-domain as measured by the number of both articles and number of journals accepting articles of this nature. It appears that this sub-domain is as large as all the other subdomains described in this study together. Within the signs and prediction sub-domain, prediction contributed the larger percentage of articles.

Thirdly, severity of the preconditions configuration appears to be mainly subjectively measured, as very few objective measures are reported. Most objective measurements are associated with the financial prediction subdomain and confirm the use of metaphors.

Fourthly, the central role of leadership (management) in the failure domain is rather substantial. Leadership's pivotal role takes effect through the following:

- Leaders' ability/skill to perceive and make sense of overloads of information describing preconditions is very important.

- Leaders' perceptions and attributions determine strategies and decision making.

- Leaders will apply biases (good or bad) when implementing decisions or learning from failure.

- Leaders have direct impact on resource munificence, continuous decision making, preconditions and stakeholder perspective. 
- Turnaround managers must overcome the "liability of leadership" to rescue firms in distress.

The style of leadership and thinking preferences of leaders are therefore antecedents of their decision-making and problem-solving abilities. The role of the human element to all the subdomains is significant and makes the analysis thereof so much more difficult.

Fifthly, as shown by Figure 1, there is substantial overlapping between the subdomains as well as the elements within them. This overlapping contributes to the complexity of distress or turnaround situations. Any research in the failure domain is therefore subject to contributions of variables that are situation specific. Generalisation should be done with care and within contextual clarification.

Finally, evaluation of any preconditions depends on judgement by individuals. Such individuals typically are subject to cognitive biases and thinking preferences (Herrmann, 1996: 43) that could be severely affected by the pressure created by the decline situation. There are, therefore, few hard and fast rules to follow for decision making, given that each situation will probably be unique.

12

\section{Contribution to business management}

Cannon and Edmondson's (2005: 299) earlier proposition states that to learn from failure intelligently requires identifying failure, analysing failure and experimenting with failure. What set out as an analysis of business failure as a phenomenon ended in the heart of the business management domain, covering more than failure and as such interfacing with subjects such as culture, change, cognition, leadership, finance, strategy and many more variables of the business and non-business environments. This confirms the interrelatedness of entrepreneurship with these issues and shows that the origins and reach of decline and failure are extensive. Characteristic of the grounded theory research approach, this was an indication of successful application of the research method, is the setting out on a course the destination of which is not clear on departure. The final adjustments to the framework happened at the very end (30 months into this project [ongoing] and after many iterations), when the sub-domains were restructured and reconceived to improve homogeneity within and heterogeneity between categories. Figure 1 also shows the extent to which some variables are associated with different sub-domains and that sub-domains also overlap each other.

The proposed failure classification framework was found to divide failure into four subdomains based on the underlying associations between the factors associated with failure. The four sub-domains are: causes and preconditions; signs and prediction; recovery; and cognition and learning. Each of the proposed sub-domains also contains several variables that determine its dimensions.

The classification framework highlighted the differences but also the close relationships between causes and preconditions and, especially, signs and prediction. The causes of decline and failure determine the eventual recovery processes and strategies to be used when attempting to turn a business around. Signs, causes and preconditions are all dependent on cognitions of the leadership and how the leaders perceive these sub-domains, which mostly determine what decision processes and strategies will be chosen for recovery attempts. Again the complexity of the interrelations is further decorated (Duchesneau \& Gartner, 1990: 298) and central to the model are three variables, namely, resource munificence, origin of the cause and leadership that act as drivers of the failure sub-domains.

\section{3}

\section{Limitations of this research}

Unfortunately all research has limitations but the limitations of one study should serve as challenges for the next.

Firstly, classification requires homogeneity within categories and heterogeneity between categories to allow for generalisation. The interrelated nature of the identified variables that make up the sub-domains restricted the 
nature of the final framework and its categories. This confirms the need for isolating groups of variables associated with different conditions but at the same time exposes the boundaries as weak and overlapping.

Secondly, the proposed framework tends to classify related and unrelated issues into "boxes" to improve understanding through analysis. The concept of preconditions described earlier is counter-classifying in principle. Using a framework therefore also has some limitations, but it is believed that its advantages outweigh the limitations if the reader considers the high level of interrelationships between subdomains and principles described in this study. The framework also does not really consider those moderating factors which mean that each failure situation has unique characteristics. Such moderating factors should receive more attention in future research.

A third limitation was probably the exclusion of some works by delineating the research as reviewing the scientific literature only, thus excluding some sources. However, these were mostly popular "how-to-do-it" books that are not necessarily driven by the research focus required for this study, and conference proceedings that normally end up as refereed papers anyway.

As a fourth limitation there appears to be a lack of recent failure literature, especially from the late 1990s, but since the new millennium some new research findings (mainly in the cognition and learning sub-domain) were reported, though this topic is hardly flooding the literature.

Finally this study gives a classification framework of the failure domain but does not really identify the drivers and moderators of the phenomenon. True to the aim of the study it assists better understanding of the phenomenon but does not explain failure mechanisms. This however should trigger the proposed future research.

\section{4}

\section{Future research}

This study identified the critical variables of business failure and suggested a platform for understanding an ill-defined phenomenon.
Extension of this research is required, especially in the direction of establishing the governing principles of the failure domain and to extend the outcome of the grounded research process (a follow-up paper is proposed). The mechanisms involved in the failure process should receive more attention. At the same time, it is hoped that scholars will find this review useful as a guiding document for the delimitation of their projects when working in this field.

Some of the findings may still appear vague and in some cases self-evident, but nevertheless; it was an enriching (yet humbling) experience to compile the review. It has contributed to the body of knowledge by adding a framework of thinking about failure. If it leads to discussion or disagreement it will have served its purpose well. Other researchers are specifically invited to critique this review and challenged to assess the proposed framework.

\section{References}

1 ALLIO, R.J. (2007) "Bad leaders: How they get that way and what to do about them", Strategy and Leadership, 38(3): 12-17.

2 ALTMAN, E.I. (1983) "Why businesses fail", Journal of Business Strategy, 3: 15-21.

3 ALTMAN, E.I. \& NARAYANAN, P. (1997)

"An international survey of business failure classification models", Financial Markets, Institutions and Instruments, 6(2): 1-57.

4 ANSIC, D. \& PUGH, G. (1999) "An experimental test of trade hysteresis: Market exit and entry decisions in the presence of sunk costs and exchange rate uncertainty", Applied Economics, 31: 427-436.

5 BACK, P. (2005) "Explaining financial difficulties based on previous payment behaviour, management background variables and financial ratios",

European Accounting Review, 14(4): 839-868.

6 BALCAEN, S. \& OOGHE, H. (2005) "35 Years of studies on business failure: An overview of the classic statistical methodologies and their related problems", The British Accounting Review, xx: 1-31.

7 BARKER III, V.L. (2005) "Traps in diagnosing organisation failure", Journal of Business Strategy, 26(2): 44-50.

8 BARKER III, V.L. \& BARR, P.S. (2002) "Linking top management attributions to strategic reorientation in declining firms attempting turnarounds", Journal of Business Research, 55: 963-976. 
9 BARKER III, V.L. \& MONÉ, M.A. (1998) "The mechanistic structure shift and strategic reorientation in declining firms attempting turnarounds", Human Relations, 51(10): 12271258

10 BAUMARD, P. \& STARBUCK, W.H. (2005) "Learning from failures: Why it may not happen", Long Range Planning, 38: 281-298.

11 BOLLEN, L.H.H.; MERTENS, G.M.H.; MEUWISSEN, R.H.G.; VAN ROAK, J.J.F. \& SCHELLEMAN, C. (2005) "Classification and analysis of major European business failures", Report by Maastricht Accounting, Auditing and Information Management Research Center (MARC), Maastricht. Accessed 14 December 2005)

12 BOYLE, R.D. \& DESAI, (1991) “Turnaround strategies for small firms", Journal of Small Business Management, 29(3): 33-42.

13 BRUNO, A.V.; MCQUARRIE, E.F. \& TORGRIMSON, C.G. (1992) "The evolution of new technology ventures over twenty years: Patterns of failure, merger and survival", Journal of Business Venturing, 7: 291-302.

14 BRUTON, G.D.; AHLSTROM, D. \& WAN, J.C.C. (2003) "Turnaround in East Asian firms: Evidence from ethnic overseas Chinese communities", Strategic Management Journal, 44(6): 519-540.

15 BURBANK, R.K. (2005) "The classic five-step turnaround process: Case study of Prodigene, Inc.", The Journal of Private Equity, Special Turnaround Issue, Spring: 53-58.

16 CAMERON, K.S.; WHETTEN, D.A. \& KIM, M.U. (1987) "Organisational dysfunctions of decline", Academy of Management Journal, 30(1): 126-138.

17 CANNON, M.D. \& EDMONDSON, A.C. (2005) "Failing to learn and learning to fail (intelligently): How great organisations put failure to work to innovate and improve", Long Range Planning, 38: 299-319.

18 CARDON, M.S. \& MCGRATH, R.G. (1999) "When the going gets tough ... Towards a psychology of entrepreneurial failure and remotivation",. Frontiers of Entrepreneurial Research, http:/www.babson.edu/fer/papers99/I/I_B/I _B\%20Text.htm. Accessed 19 April 2005.

19 CARROLL, P.B. \& MUI, C. (2008) "Seven ways to fail big”, Harvard Business Review, September: 82-91.

20 CHARITOU, A.; NEOPHYTOU, E. \& CHARALAMBOUS, C. (2004) "Predicting corporate failure: Empirical evidence for the UK", European Accounting Review, 13(3): 465-497.
21 CHOWDHURY, S.D. \& LANG, J.R. (1993)

"Crisis, decline and turnaround: A test of competing hypothesis for short-term performance improvement in small firms", Journal of Small Business Management, 31(4): 8-17.

22 CHRISMAN, J.J.; HOFER, C.W. \& BOULTON, W. R. (1988) "Toward a system for classification of business strategies", Academy of Management Review, 13(3): 413-428.

23 COLLARD, J.M. (2002) "Steering clear of the brink: Early warning signs pinpoint business troubles - Changing leadership style to accomplish a turnaround", The Journal of Private Equity, Fall: 25-31.

24 CONGER, J.A. \& NADLER, D.A. (2004) "When CEOs step up to fail", MIT Sloan Management Review, Spring: 50-56.

25 COPE, J. (2003) "Entrepreneurial learning and critical reflection: discontinuous events as triggers for 'higher level' learning", Management Learning, 34(4): 429-450.

26 CORBIN, J. \& STRAUSS, A. (1990) "Grounded theory research: Procedures, canons and evaluative criteria”, Qualitative Sociology, 13(1): 3-21.

27 CRESSY, R. (2006) "Why do most firms die young?", Small Business Economics, 26: 103-116.

28 CRUTZEN, N. \& VAN CAILLIE, D. (2007) "The business failure process: Towards an integrative model of the literature", Working paper. HECULG University de Leige. No 200705/02: 1-32.

29 CYBINSKI, P. (2001) "Description, explanation, prediction: The evaluation of bankruptcy studies?", Managerial Finance, 27(4): 29-44.

30 D'AVENI, R.A. (1989) "The aftermath of organisational decline: a longitudinal study of the strategic and managerial characteristics of declining firms", Academy of Management Journal, 32(3): 577-608.

31 DE CASTRO, J.O.; ALVAREZ, S.A.; BLASICK, J.D. \& ORTIZ, M. (1997) "An examination of the nature of business closings: Are they really failures?", Frontiers of Entrepreneurship Research, http://www.babson.edu/entrep/ fer/papers97/ decastro/. Accessed: 10 March 2005.

32 DUCHESNEAU, D.A. \& GARTNER, W.B. (1990) "A profile of new venture success and failure in an emerging industry", Journal of Business Venturing, 5: 297-312.

33 EISENHARDT, K.M. \& ZBARACKI, M.J. (1992) "Strategic decision making", Strategic Management Journal, 13, Special Issue, Winter: 17-37.

34 FORBES, D.P. (1999) "Cognitive approaches to new venture creation”, International Journal of Management Reviews, 1(4): 415-439. 
35 FRANCIS, J.D. \& DESAI, A.B. (2005)

"Situational and organisational determinants of turnaround", Management Decision, 9: 1203-1224.

36 FREDLAND, J.E. \& MORRIS, C.E. (1976) "A cross section analysis of small business failure", American Journal of Small Business, 1(1): 7-18.

37 GIMENO, J., FOLTA, T.B. \& WOO, C.Y. (1997) "Survival of the fittest? Entrepreneurial human capital and the persistence of underperforming firms", Administrative Science Quarterly, 42: 750783.

38 HAMBRICK, D.C. \& SHECTER, S.M. (1983)

"Turnaround strategies for mature industrialproduct business units", Academy of Management Journal, 26(2): 231-248.

39 HARKER, M. \& SHARMA, S. (2000)

"Leadership and the company turnaround process", The Leadership and Organisation Development Journal, 21(1): 36-47.

40 HENDERSON, A.D. (1999) "Firm strategy and age dependence: A contingent view of the liabilities of newness, adolescence and obsolescence", Administrative Science Quarterly, 44: 281-314.

41 HERRMANN, N. (1996) "The Whole Brain Business Book, New York: McGraw-Hill.

42 HOFER, C.W. (1980) "Turnaround strategies", The Journal of Business Strategy, 1(1): 19-31.

43 HOPKINS, H.D. (2008) "Successful turnaround strategies", Strategic Direction, 24(8): 3-5.

44 INKPEN, A. (1995) "The seeking of strategy where it is not: Towards a theory of strategy absence", Strategic Management Journal, 16: 313332.

45 KALE, S. \& ARDITI, D. (1998) "Business failures: Liabilities of newness, adolescence, and smallness", Journal of Construction Engineering and Management, November/December: 458-464.

46 KEASEY, K. \& WATSON, R. (1987) "Nonfinancial symptoms and the prediction of small company failure: A test of Argenti's hypothesis", Journal of Business Finance and Accounting, 14 (3): 335-354.

47 KEASEY, K. \& WATSON, R. (1991) "Financial distress prediction models: A review of their usefulness", British Journal of Management, 2: 89102.

48 KNOTT, A. \& POSEN, H.E. (2005) "Is failure good?", Strategic Management Journal, 26: 617-641.

49 KOW, G. (2004) "Turning around business performance: Part 1", Journal of Change Management, 4 (3): 229-246.

50 KRIEGESMANN, B., KLEY, T. \& SCHWERING, M.G. (2007) "Making organisational learning happen: The value of “creative failures"”, Business Strategy Series, 8 (4): 270-276.

51 LAITINEN, T. \& KANKAANPÄÄ, M. (1999)

Comparative analysis of failure prediction methods: The Finnish case", The European Accounting Review, 8 (1): 67-92.

52 LE ROUX, I.; PRETORIUS, M. \& MILLARD, S.M. (2006) "Entrepreneurial cognition and the decision to exploit a venture opportunity", South African Business Review, 10(10): 5-69.

53 LONGENECKER, C.O.; NEUBERT, M.J. \& FINK, L.S. (2007) "Causes and consequences of managerial failure in rapidly changing organisations", Business Horizons, 50: 145-155.

54 LONGENECKER, C.O.; SIMONETTI, J.L. \& SHARKEY, T.W. (1999) "Why organisations fail: The view from the frontline", Management Decision, 37 (6): 503-513.

55 LORANGE, P. \& NELSON, R.T. (1987) "How to reorganize - and avoid - organisational decline", Sloan Management Review, 28(3): 41-46.

56 LOVALLO, D. \& KAHNEMAN, D. (2003) "Delusions of success", Harvard Business Review, July: 56-63.

57 LUSSIER, R.N. (1995) "A non-financial business success versus failure prediction model for young firms", Journal of Small Business Management, 33 (1): 8-24.

58 LUSSIER, R.N. \& PFEIFER, S. (2001) "A crossnational prediction model for business success", Journal of Small Business Management, 39 (3): 228-249.

59 MCGRATH, R.G. (1999) "Falling forward: Real options reasoning and entrepreneurial failure", Academy of Management Review, 24 (1): 13-30.

60 MELLAHI, K. (2005) "The dynamics of boards of directors in failing organisations", Long range planning, 38: 269-279.

61 MERRIAM-WEBSTER ONLINE DICTIONATY. (2008) http://www.merriamwebster.com/dictionary/cause. Accessed: 9 September 2008.

62 MOSS KANTER, R. (2003) "Leadership and the psychology of turnarounds", Harvard Business Review, June: 58-67.

63 OKPARA, J.O. \& WYNN, P. (2007)

"Determinants of small business growth constraints in a sub-Saharan African economy", SAM Advanced Management Journal, 72(2): 24-35.

64 OOGHE, H. \& DE PRIJCKER, S. (2008) "Failure processes and causes of company bankruptcy: A typology. Management Decision, 46 (2): 223-242.

65 PANDIT, N.R. (1995) "Towards a grounded theory of corporate turnaround: A case study approach", 
Unpublished Doctoral thesis. University of Manchester, UK.

66 PEARCE II, J.A. \& MICHAEL, S.C. (2006)

"Strategies to prevent economic recessions from causing business failure", Business Horizons, 49: 201-209.

67 PEARCE II, J.A. \& ROBBINS, D.K. (1993)

"Towards improved theory and research on business turnaround", Journal of Management, 19(3): 613-636.

68 PEARCE II, J.A. \& ROBBINS, D.K. (1994)

"Retrenchment remains the foundation of business turnaround", Strategic Management Journal, 15: 407-417.

69 POMPE, P.P.M. \& BILDERBEEK, J. (2005) "The prediction of bankruptcy of small- and medium-sized industrial firms", Journal of Business Venturing, 20: 847-868.

70 PRETORIUS, M. (2008) “When Porter's generic strategies are not enough: Complementary strategies for turnaround situations", Journal of Business Strategy, Nov-Dec. In Press.

71 PRETORIUS, M. \& HOLTZHAUZEN, G.T.D. (2008) "Critical variables of venture turnarounds: A liabilities approach", Southern African Business Review, 12(2): 87-107.

72 PROBST, G. \& RAISCH, S. (2005)

"Organizational crisis: The logic of failure", Academy of Management Executive, 19(1): 90-105.

73 RICHARDSON, B.; NWANKWO, S. \& RICHARDSON, S. (1994) "Understanding the causes of business failure crisis: Generic failure types: boiled frogs, drowned frogs, bullfrogs \& tadpoles", Management Decision, 32 (4): 9-22.

74 ROBBINS, D.K \& PEARCE II, J.A. (1992)

"Turnaround: retrenchment and recovery", Strategic Management Journal, 13(4): 287-309.

75 SCHERRER, P.S. (2003) "Management turnarounds: Diagnosing business ailments", Corporate Governance, 30(4): 52-62.

76 SHEPHERD, D.A. (2003) "Learning from business failure: Propositions of grief recovery for the self-employed", Academy of Management Review, 28(2): 318-328.

77 SHEPHERD, D.A. (2005) "The theoretical basis for my plenary speech about our successes and failures at research on business failure", Proceedings: Regional Frontiers of Entrepreneurial Research, Brisbane. February: 123-134. Invited paper.

78 SHEPHERD, D.A.; WICKLUND, J. \& HAYNIE, J.M. (2007) "Moving forward: Balancing the financial and emotional costs of business failure", Journal of Business Venturing, 28(2): 318-328.
79 SHEPPARD, J.P. \& CHOWDHURY, S.D. (2005)

"Riding the wrong wave: Organisational failure as a failed turnaround", Long Range Planning, 38: 239-260.

80 SMITH, M. \& GRAVES, C. (2005) "Corporate turnaround and financial distress", Managerial Auditing Journal, 20(3): 304-320.

81 STANWORTH, J.; PURDY, D.; PRICE, S. \& ZAFARIS, N. (1998) "Franchise versus conventional small business failure in the US and UK: More similarities than differences", International Small Business Journal, 16(3): 56-70.

82 STEAD, E. \& SMALLMAN, C. (1999)

"Understanding business failure: learning and unlearning lessons from industrial crises", Journal of Contingencies and Crisis Management, 7(1) March: 1-18.

83 STEYN-BRUWER, B.W. \& HAMMAN, W.D. (2006) "Company failure in South Africa. Classification and prediction by means of recursive partitioning", South African Journal of Business Management, 37(4): 7-18.

84 SUDARSANAM, S. \& LAI, J. (2001) "Corporate financial distress and turnaround strategies: An empirical analysis", British Journal of Management, 12: 183-199.

85 THENG, L.G. \& BOON, L.W. (1996) "An exploratory study of factors affecting the failure of local small and medium enterprises", Asia Pacific Journal of Management, 13(2): 47-61.

86 THORNHILL, S. \& AMIT, R. (2003) "Learning about failure: Bankruptcy, firm age, and the resource-based view", Organisational Science, 14 (5) September-October: 497-509.

87 UNIVERSAL DICTIONARY (1988) Readers Digest Universal Dictionary, London: Readers Digest.

88 WALSHE, K.; HARVEY, G.; HYDE, P. \& PANDIT, N. (2004) "Organisational failure and turnaround: Lessons for the public services from the for-profit sector", Public Money and Management, August: 201-208.

89 WEITZEL, W.F. \& JONSSON, E. (1989) "Decline in organisations: A literature integration and extension", Administrative Science Quarterly, 91 March: 91-109.

90 WEITZEL, W.F. \& JONSSON, E. (1991) "Reversing the downward spiral: lessons from W.T. Grant and Sears Roebuck", Academy of Management Executive, 5(3): 7-21.

91 ZACHARAKIS, A.L., MEYER, G.D. \& DE CASTRO, J. (1999) "Differing perceptions of new venture failure: A matched exploratory study of venture capitalists and entrepreneurs", Journal of Small Business Management, 37(3): 1-14. 